\title{
Diabetes treatment with insulin glargine and risk of malignancy: methodological pitfalls and ethical issues
}

\author{
D. Simon
}

Received: 4 September 2009 / Accepted: 22 September 2009/Published online: 27 October 2009

(C) The Author(s) 2009. This article is published with open access at Springerlink.com

Keywords Allocation bias · Causality $\cdot$ Ethics $\cdot$ Inclusion criteria $\cdot$ Methodological pitfalls $\cdot$ Multiple comparisons $\cdot$ Observational studies $\cdot$ Over-adjustment $\cdot$ Randomised controlled trials

To the Editor: In their recent paper, Hemkens et al. conclude that their 'results based on observational data support safety concerns surrounding the mitogenic properties of glargine in diabetic patients', because given 'the overall relationship between insulin dose and cancer, and the lower dose with glargine, the cancer incidence with glargine was higher than expected compared with human insulin' [1]. Indeed, if it is obvious that the mean daily insulin dose was lower in insulin glargine compared with human insulin users $(25.9 \pm 22.5$ vs $43.8 \pm 37.4 \mathrm{IU})$, and if, using models to adjust for a few potential confounders, a higher incidence of malignant neoplasms was found with insulin glargine at similar insulin dose, in our opinion, this does not support any safety concern surrounding the mitogenic properties of insulin glargine in diabetic patients. I will demonstrate this in two steps.

First, over-adjustment for insulin doses should be considered. Unfortunately, Hemkens et al. did not report data concerning glycaemic control. If identical glycaemic

D. Simon

INSERM U-780,

94807 Villejuif Cedex, France

D. Simon $(\triangle)$

Service de Diabétologie, Hôpital de la Pitié,

47 boulevard de l'Hôpital,

75013 Paris, France

e-mail: dominique.simon@psl.aphp.fr control had been obtained in the treatment groups, using lower doses in insulin glargine users, adjustment for insulin dose would not have been appropriate. However, two randomised clinical trials in which insulin glargine and NPH insulin were up-titrated to reach identical glycaemic targets have shown no difference between insulin glargine and human insulin in terms of the dose needed: $68 \pm 39$ vs $70 \pm 42$ IU (NS) in the Lantus plus Metformin (LANMET) Study [2], and $32.1 \pm 17.6$ vs $32.8 \pm 18.9$ IU (NS) in the Lantus Evaluation in Asian Diabetics (LEAD) Study [3], respectively. Furthermore, the Treat-to-Target Trial reported that higher doses of insulin glargine were needed: $47.2 \pm 24.9$ vs $41.8 \pm 25.6$ IU $(p<0.005)$ [4]. Therefore, the hypothesis of over-adjustment can be ruled out, and it can be deduced that poorer glycaemic control was achieved in the insulin glargine-treated group in the study by Hemkens and colleagues [1], as it was in the Scottish diabetic population studied [5]. It is thus important to understand the reason why a higher glycaemic target was set for the patients treated with insulin glargine. As a positive association between the length of exposure to high levels of plasma glucose and the risk of developing diabetesrelated microvascular complications has been demonstrated [6] and is well known by physicians, the most probable explanation for the less ambitious glycaemic control aimed for in the insulin glargine-treated group is that these patients were considered by their practitioners to have a shorter life expectancy than those treated by other insulin regimens. This suggests an allocation bias to be present in the study by Hemkens et al. [1], as acknowledged by the SDRN Epidemiology Group in the Scottish paper [5]. As the insulin glargine users were not older than the human insulin users (69.5 \pm 11.6 vs $69.6 \pm 13.1$ years, respectively), it probably means that they were in worse health. This is 
not obvious from the few baseline characteristics shown in Table 1 of the paper by Hemkens et al., which were used for multiple adjustments. Therefore, one can only speculate on the reasons why the insulin glargine-treated patients were supposed to have a shorter life-expectancy in their practitioner's mind, and can only imagine the characteristics that differed between the two groups at baseline that could not, unfortunately, be adjusted for. As the authors conclude that there is a higher cancer incidence during the very short follow-up period (mean 1.63 years, median 1.41 years), a possible explanation, the simplest, is that, at least for some of the diabetic patients treated with insulin glargine, the practitioner knew they had a cancer that was not yet registered in the health insurance fund. Indeed, this provocative suggestion becomes plausible when one examines the procedures used to select 'adult patients without known malignant disease', as the authors state that they 'considered participants to be without known malignant disease if they had not received a corresponding diagnosis within 3 years prior to inclusion in the study', and that they 'excluded participants with the slightest suspicion of a malignant disease (e.g. patients with the ICD-10 [International Classification of Diseases, 10th revision, German Modification] diagnosis Z03.1—observation for suspected malignant neoplasm)' [1]. This information seems to mean that the coding forms in the hospital records were the only source for diagnosing a previous cancer and to exclude an insulin-treated diabetic patient. Table 1 of the paper [1] shows that the insulin glargine-treated patients had been hospitalised less often than the human insulin users in the three preceding years $(35.5 \%$ had one or two hospital stays, and $16.2 \%$ had more than two hospital stays vs $41.3 \%$ and $23.4 \%$, respectively, $p<0.0001$ ). Thus, the explanation for the results reported could be that some diabetic patients having a recent cancer were included by error. Their practitioner knew they had cancer, treated them with insulin glargine and set the glycaemic target at a higher level, using lower insulin doses. As they had not yet been hospitalised, cancer had not been notified to the health insurance fund.

Second, in spite of multiple comparisons and multiple models, we are told that because the study was intended to generate hypotheses, no adjustments were made for multiple testing' [1], and a paper whose author list includes Bender, a coauthor of the Hemkens et al. study, is cited to justify that decision [7]. In the paper by Bender and Lange it is written that "Significant" results based upon exploratory analyses should clearly be labelled as exploratory results. To confirm these results the corresponding hypotheses have to be tested in further confirmatory studies.' [7]. Indeed, even if we can accept this opinion in general, which could be challenged, it is unacceptable in the situation of diabetes treatment and cancer risk, as no confirmatory study using a randomised design can be performed now or in the future to validate, or, more probably, to refute the hypothesis of a causal association between insulin glargine and cancer risk, for obvious ethical and practical reasons. Therefore, to have raised a scientific issue that will never be resolved, by using a flawed methodology, is unethical.

In conclusion, probably the right and safe decision would have been to adopt the opinion of the three of the six referees who initially recommended rejection [8], and not publish the study by Hemkens et al., especially given that the Editorial accompanying the publication states: 'There is no evidence of an overall increase in the rate of cancer development in patients on insulin glargine, and some suggestion that the risk may actually be reduced.' [8]. Unfortunately, the rumour is spreading now, and it is a pity to have troubled for a long time, probably forever, many diabetic patients who were using glargine insulin, often with great satisfaction, as well as their care providers.

Duality of interest I acknowledge that I have served on speakers bureaus of Glaxo-Smith Kline, sanofi-aventis, Servier; I have served on advisory panels for Astra-Zeneca, Bristol Myers Squibb, Fournier, Glaxo-Smith Kline, Novartis and Pfizer; I have received research funding from Lilly-France; and I have written a chapter of a book sponsored by Takeda.

Open Access This article is distributed under the terms of the Creative Commons Attribution Noncommercial License which permits any noncommercial use, distribution, and reproduction in any medium, provided the original author(s) and source are credited.

\section{References}

1. Hemkens LG, Grouven U, Bender R et al (2009) Risk of malignancies in patients with diabetes treated with human insulin or insulin analogues: a cohort study. Diabetologia 52:1732-1744

2. Yki-Järvinen H, Kauppinen-Mäkelin R, Tikkainen M et al (2006) Insulin glargine or NPH combined with metformin in type 2 diabetes: the LANMET study. Diabetologia 49:442-451

3. Pan CY, Sinnassamy P, Chung KD, Kim KW, on behalf of the LEAD Study Investigators Group (2007) Insulin glargine vs NPH insulin therapy in Asian type 2 diabetes patients. Diabetes Res Clin Pract 76:111-118

4. Riddle MC, Rosenstock J, Gerich J, on behalf of the Insuline Glargine 4002 Study Investigators (2003) The Treat-to-Target Trial: randomized addition of glargine or human NPH insulin to oral therapy of type 2 diabetic patients. Diabetes Care 26:3080-3086

5. Colhoun HM, SDRN Epidemiology Group (2009) Use of insulin glargine and cancer incidence in Scotland: a study from the Scottish Diabetes Research Network Epidemiology Group. Diabetologia 52:1755-1765 Erratum 52:2469

6. UK Prospective Diabetes Study (UKPDS) Group (1998) Intensive blood-glucose control with sulphonylureas or insulin compared with conventional treatment and risk of complications in patients with type 2 diabetes (UKPDS 33). Lancet 352:837-853

7. Bender R, Lange S (2001) Adjusting for multiple testing-when and how? J Clin Epidemiol 54:343-349

8. Smith U, Gale EAM (2009) Does diabetes therapy influence the risk of cancer? Diabetologia 52:1699-1708 